\title{
Railway operations and safety in Indonesia: a descriptive study
}

\author{
H. Iridiastadi \\ Faculty of Industrial Technology, \\ Institut Teknologi Bandung, Indonesia
}

\begin{abstract}
The Indonesian railways have been growing substantially in the past few years. The development of mass rapid and light rail transit is underway, and more railway networks in various regions will be implemented in the near future. Despite the increased complexity of railway operations, the corresponding safety issues have not been addressed adequately. This study will report railway operations currently in place in Indonesia and, furthermore, describe how they potentially relate to safety. This objective was achieved mainly through a review of secondary data and past studies conducted by the researcher and colleagues. It is concluded here in this report that risks of railway incidents in the future are still present. Efforts to minimize the risks should involve relevant stakeholders, including local government, the ministry of transportation, and rail operator. A systematic database and theoretically sound methodology need to be employed in understanding the root cause of the accidents and as a basis for strategic safety interventions. At the organizational level, a fatigue management system (FMS) needs to be implemented within the larger context of safety system.

Keywords: railway, safety, fatigue management, Indonesia.
\end{abstract}

\section{Introduction}

Railway safety has generally received sufficient attention, particularly in many industrialized nations [1]. Attempts at improving safe train operations train have come in the form of advanced technology implementations, the development of standards and procedures, or newer facilities and infrastructures. Despite these efforts, however, railway incidents have still occurred lately, such as in Western 
Europe or in the United States of America. While the number of fatalities is probably minimal, the consequences could still be catastrophic.

Safe train operations have also been a challenging issue in many developing countries. In Indonesia, the infrastructures for mass rapid and light rail transit are currently being built in many major cities. Additional rail networks in different regions have been planned and developed, which include commuter and urban transport. In addition, double tracks have been developed in the past few years that allows for increased frequency of passenger as well as freight train trips.

Despite the increase in train operations complexity, safety issues have not been addressed adequately. Concerted efforts in improving railway safety have been conducted by different stakeholders, and the results have been relatively promising. Nevertheless, incidents in the form of train collisions have still occurred in the past years. Derailments and level crossing accidents occur frequently and the latter, in particular, have been reported in the media every other month or so.

This paper is a report that aimed at describing railway operations in Indonesia. This report will also provide an initial understanding on safety issues that are closely associated with the characteristics of such operations. It is expected that insights from this report can benefit researchers in this area, particularly those who are not familiar with the more conventional operations of railway system in Indonesia.

\section{Methods}

To achieve the objective noted above, three different methods were utilized. First, this study obtained information from various sources of information pertaining to Indonesian railway system. These include scientific papers, national and local newspapers, as well as other information available from the Internet.

Second, this report was also based on field observations and discussions with railway stakeholders. In addition, interviews were conducted to certain personnel to discuss issues pertaining to their jobs. It should be noted that all these techniques were employed as part of the methods used in different studies.

Lastly, this report was also written based on data and findings from previous studies in Indonesia, particularly those addressing human factors issues. The topics of such studies varied, ranging from human errors to occupational workload among railway personnel, to risks at level intersections.

\section{Results}

\subsection{Current operating conditions}

The Indonesian Ministry of Transportation is responsible for providing the railway infrastructures, while a state-owned company (PT. Kereta Api Indonesia/PT. KAI) acts as the operator. Both passenger and freight train services are available, with the majority of the former being located in Java Island. A commuter line network is currently serving the Indonesian Capital of Jakarta and the surrounding cities. 
Some of the cities served by long-distance train are located at greater than 800 meters above sea level, and tracks inclination of $1 \%$ is not uncommon.

PT. KAI operates somewhat aging locomotives, with the majority have been in operation for roughly 10-40 years. The cabins are generally not air-conditioned, and the temperature inside the cabins can be as high as $35^{\circ} \mathrm{C}$ (a WBGT of $28^{\circ} \mathrm{C}$ ). A noise level between 67 to $101 \mathrm{dBA}$ is fairly common. Note that train horns are used very frequently to alert people along the tracks or when approaching level crossings. Ergonomic work postures are probably difficult to achieve, considering the chair and cabin layout are not designed for Indonesian population.

There are basically two types of railway personnel - on board and "land" personnel. On board personnel are those who perform their jobs on the train, and (for a passenger train) typically include a train conductor, a manager on duty, a train driver, driver's assistant, technician, and a few security personnel and cleaning crews. Several wait staffs are also present, mainly to help with informational needs and providing meals to passengers. On board the commuter train are the driver and several crew members (engineer, security, and cleaning personnel).

Land personnel include those who work in train stations and those who are responsible for closing and opening the gates at level crossings. A 'PPKA' is an individual who is responsible for scheduling and controlling of train journeys. Holding a vital role, this person ensures that no two trains are running on the same tracks, and is formally required to stand up straight next to railway tracks when a train passes a station. This person controls various rail signals, either manually or electronically. In large stations, an assistant to a PPKA is usually available on the station platform to help as a signalman.

Before the devastating Petarukan collision in October 2010, each train driver typically worked two four-hour sessions per day, with at least two hours of rest between sessions. Currently the 8-hour task is only given to commuter line drivers. Additional one work hour is given prior to and immediately after driving the train. The roster is somewhat not fixed, and the drivers need to find out their next schedules two days ahead of time. Commuting time (to and from work) is usually around 1-2 hours.

The train driver (and to a lesser extent the assistant driver) is usually an individual with the highest responsibility with respect to train safety during a particular trip. The driver controls the train speed, and has to pay a great deal of attention to railroad signals, signs, and potential hazards (e.g., floods or landslides). Instructions from the central command are received mainly via radio communication. The same technology is also used for communicating among drivers on duty.

In general, the present technologies (i.e. communication, signals, controls) are not considered advanced, and their reliability may be linked to safety issues. Railway signals struck by lightning that causes major traffic disruption is an example of common phenomenon. Other safety issues that need major considerations is the fact that the people often lives and do their business adjacent to (or sometimes on) the railroad tracks. Interference to the train journey can be in the form of reduced speed or vigilance to the local people throwing rocks onto 
the train. Additionally, there are nearly 8,400 registered level crossings in Java and Sumatera Islands. Only about $14 \%$ of these crossings are guarded. Note that additional thousands of small, unregistered level crossings have also been created due to the need arising from local activities.

In one of our studies, fatigue and stress among 160 train drivers were evaluated using several methods available in the literature. A large proportion (74\%) were smokers, which is a common phenomenon among general worker population in Indonesia. Based on the survey utilizing NASA-TLX [2], mental demand is considered as the most demanding dimension of workload. Using Subjective Workload Assessment Technique/SWAT [3], the researchers found time pressure as one of the most stressful requirements when performing the job. Stress was measured by analyzing levels of salivary alpha amylase (SAA). Based on the criteria proposed by Yamaguchi and Sakakima [4], nearly $71 \%$ of the train drivers experienced excessive stress (i.e. SAA levels of greater than $60 \mathrm{kU} / \mathrm{l}$ ) prior to train departures. This figure declined to roughly $60 \%$ of the subjects following the end of a trip. Finally, the NIOSH General Job Stress Questionnaires indicated that roughly $90 \%$ of the subjects felt the cabin physical environment as stressful, and about $80 \%$ indicated mental demand and responsibility associated with the task.

Also investigated in our study was fatigue and stress among controllers and other personnel working at train stations. Findings from this study demonstrated that the majority of the workers (94\%) experienced stressful work conditions (as indicated by higher levels of salivary amylase). Furthermore, shiftwork substantially affected performance (as measured by psychomotor vigilance task/PVT), fatigue (measured by Swedish Occupational Fatigue Inventory/SOFI), and sleepiness (measured by the Karolinska Sleepiness Scale). Night shifts, in particular, resulted in increased (40-160\%) fatigue and slower (5-70\%) reaction time. While shiftwork clearly has adverse impact on safety, the management has never studied this issue comprehensively.

\subsection{Statistics}

Two government institutions are directly responsible for railway safety, including the operator (PT. KAI) and the Directorate General for Railway within the Ministry of Transportation. The National Committee for Transportation Safety (KNKT) via the railway division investigates railway accidents, and recommends the required interventions. The first two government entities are responsible for reporting safety statistics to the public. The data, however, are often different from one institution to the other, and up-to-date statistics are not readily available for the public. Currently, no database has been developed that stores and describes every incident in a systematic fashion.

A total of 661 railway accidents occurred between 2005 and 2010. Roughly $16.5 \%$ are incidents at level crossings, whereas nearly $66.6 \%$ are those associated with train derailments. Train collisions represent about $4.4 \%$ of the total rail incidents, while the rest (12.5\%) are those that belong to miscellaneous category. These incidents resulted in 282 deaths and 1,149 injured. Statistics beyond the year of 2010 are fairly scarce, but the media have reported only several major accidents in the past five years. According to KNKT, the rate of accident (i.e. the 
number of accidents/distance travelled in million $\mathrm{km}$ ) has declined steadily, from about 0.3 in 2007 to 0.04 in 2013 . The costs associated with these accidents varied, but thousands of dollars of direct financial loss can be expected for some minor incidents. A serious derailment may result in about 8 billion rupiahs ( $\sim 600$ thousand USD) of economic loss. This figure may double in case of accident involving heavily damaged locomotives.

The Directorate General for Railway suspected that $35 \%$ of these incidents had to do with human factors, while about $20 \%$ were associated with external factors. More than $40 \%$ were due to poor railway facilities and infrastructures. In many cases, the term human error has been used very loosely, and is seldom described in detail. When an accident occurs, those directly involved (e.g., the train driver or crossing guard personnel) will be held responsible, and will usually be questioned and detained by the police. According to KNKT, the human aspects involved train controller gives wrong signals or asleep. Similarly, the train driver can be asleep while operating the train, or unaware of an important signal.

Based on Human Factors Analysis and Classification System or HFACS [5], Iridiastadi and Ikatrinasari [6] were able to identify 72 factors that contributed to major rail accidents (investigated by KNKT). Of these, $22 \%$ had to do with unsafe operator acts. About $39 \%$ of the factors were categorized into preconditions for unsafe acts. Supervisory factors were related to $14 \%$ of the identified factors, while $25 \%$ of the factors dealt with organizational factors.

\section{Discussion}

As opposed to those in industrialized nations, railway operations in Indonesia still rely heavily on more conventional system and technologies. Locomotives are not equipped with air conditioned cabin, nor more modern control and communication system. Additionally, level crossings are very prevalent and a substantial portion of these is not guarded. Typically, gates at level crossings are activated manually, but poor behaviors of the passing motorists often compromise the effectiveness of the gates.

The number of train collisions has reduced substantially in the past five years. It should be noted, however, that such incidents still occur approximately every other year (the last one being in 2015). Both train derailments and accidents at level crossings are still fairly common phenomena. The latter is generally caused by motorists trying to run the activated gates or those who are trapped on the railroad track due to traffic jams.

According to KNKT report, human error has been labeled to at least $80 \%$ of major railway incidents, with roughly $45 \%$ of this committed by the train drivers. In India, close to $60 \%$ of train accidents are associated with poor performance of train drivers [7]. The work of Kim et al. [8] noted that $61 \%$ of railway accidents are related to human errors.

It is worth noting that the term 'human error' has likely been used very loosely among different institutions (even in the literature), and also without proper operational definitions. The drawbacks are that comparisons between cases are difficult to make, and an in-depth investigation on the root cause of an accident is 
more difficult. In many cases, front-line personnel (e.g., a train driver or a controller) have been held responsible for an accident (and have to face jail time), but the root causes have never been investigated systematically. This leads to difficulties in determining other factors within the organization that may also play an important role in the accident. The use of HFACS (or any similar technique) as a method for identifying causes of accident is strongly suggested. In fact, coupled with a good incident database, such method may produce invaluable insight on the most effective intervention strategy for improving railway safety.

Note that current laws state that trains have the right of way when passing at level crossings. Assuming that the barriers have been properly activated, this implies that railway operator cannot be held responsible when such an accident occurs. Consequently, the current practice is that the operator will not do any intervention program to prevent the accidents from occurring. While this may be true from the legal standpoint, it is strongly suggested here that the operator takes a proactive approach in minimizing accidents at level crossings. Several programs can be initiated, including close cooperation with local government and educating the public on safe driving. More importantly, Indonesian motorists may have different culture and habit with respect to discipline and safe driving. Heavy penalties may have to be really enforced to motorists breaking traffic laws. Considering that many motorists have poor behaviors, substantial modifications to "standard" barriers, warning signs, and alarms should also be done.

In spite of the seemingly marginal workload, train driving in Indonesia can be fairly demanding due to several reasons. First, the cabins are generally not equipped with air conditioners, that some of the cab windows are usually kept open. Such a condition degrades air quality inside the cabin and the drivers have to cope with uncomfortable levels of external noise. Communication to the central command is also a challenging issue because of the technology used and the level of noise present. This poor physical work environment may certainly result in increased fatigue and stress.

Second, fatigue and sleepiness may exist as a result of a number of task characteristics. For example, inter-city train driving has been associated with a relatively high level of monotony, and such characteristic can lead to sleepiness and reduced performance [9]. In fact, our electroencephalography (EEG) study investigating monotony during simulated train driving demonstrated steeper increase in alpha and theta waves compared to driving in dynamic situations. Moreover, train drivers in Indonesia may not receive a fixed and predictable work schedule. The sleep quality and duration may not be sufficient due to lack of comfortable and representative rest/sleeping area. Adequate sleep quality may indeed be an issue even when the drivers are back to their homes. However, this has never been studied further.

Lastly, it is not uncommon for the train drivers to experience high level of stress due to hazardous railroad conditions. Aside from poor track conditions that could likely result in derailments, the drivers have to look out for sabotage activities. Examples of these include people throwing rocks onto the train, or those cutting/stealing components of the track. Many other hazardous conditions can be observed when driving through level crossings. Accidents due to motorists 
running the barriers are relatively frequent, and drivers experiencing fatal accidents before their eyes are not uncommon.

The issues of fatigue, sleepiness, and stress to date have not received adequate attention. Similarly, for determining fitness for duty, the only measurements obtained prior to any scheduled duty are heart rate, body temperature, and blood pressure. These measures may not be directly related to the driver's readiness for performing his duty, nor can they be used as an indication of level of fatigue. Additionally, these measures are not saved into a system (i.e. a database) that might allow for further interpretations regarding drivers' fatigue profile.

The issues noted above also characterize controllers and other station's personnel. Unfortunately, the management has not addressed these in a comprehensive manner. Fatigued and sleepy controllers play an important role in some of the accidents, but this has only resulted in disciplinary actions. No systematic investigation has been carried out that describes what approach should be taken to minimize fatigue risk.

To mitigate fatigue risks, PT. KAI could implement an approach that is based on a more complete fatigue management system [10], which puts responsibility at regulatory, company, and individual levels. Current national laws (UU No. 22/2009) generally only limit working hours (a maximum of 8 hours of driving and a minimum of 1 hour of rest; 12 hours is possible, which include 1 hour of rest). This does not take into account a number of factors, such as the amount (and quality) of sleep or time awake. Following the major accident in 2010, PT. KAI implement 4 hour or work (at operational level, permits somewhat random scheduling). No regulations apply specifically to railway industry. Laws specific to this industry probably are thus suggested. From the regulatory point of view, PT. KAI should now be required to implement FMS (or other similar systems).

At the organizational-individual level, quantitative models that predict fatigue and performance could be employed as a potential alternative. The models reported by Dorrian et al. [11], Roach et al. [12], or Spencer et al. [13], for example, could be used to assess fatigue level based on one's sleep/wake schedules and previous rosters. More objective measures of fatigue could also be employed, including the use of Psychomotor Vigilance Task or PVT [14], blinks and eye behavior [15], or biological markers [4]. Additional considerations should also be given to personnel working during night shift, particularly due to the likelihood of sleepiness associated with disturbed circadian rhythm [11]. In sum, the operator should initiate a strategic and comprehensive program that addresses fatigue as a very potential safety risk. Without such a program, there is a likelihood that (major) accidents will persist in the future, and root causes of these railway accidents are difficult to reveal.

\section{Conclusion}

This study aimed at describing safety statistics and potential contributing factors to these incidents. In addition, this study evaluated railway operating conditions related to human aspects that could lead to an incident. Statistics on railway safety were compiled by studying documents available at the Ministry of Transportation 
and PT. Kereta Api Indonesia (PT. KAI) as the sole train operator in Indonesia. Data were also obtained from the National Committee on Transportation Safety and, together with results from our study, explained factors that contributed to railway incidents. Information on the human aspects of railway operations was collected via surveys and interviews to railway officials in nine railway operational regions. Results of this study indicate differences in safety statistics among government institutions. About 50 to $60 \%$ of these incidents were related to human operators, while the rest were associated with management of railway operations and environmental factors. Three groups of human operators frequently associated with the incidents were the train drivers, controllers, and the guards who activate gates/barriers at railroad crossings. Operating conditions that could influence performance of human operators included stressful work (and environmental) conditions, night shifts, monotony, and time on task. It was also found that, in practice, rosters were not followed strictly that resulted in longer task durations. Additionally, the railway company currently does not have adequate fatigue management system. This paper suggests improvements that can be conducted to ameliorate railway safety in Indonesia.

\section{References}

[1] Silla, A., \& Kallberg, V-P. The development of railway safety in Finland. Accident Analysis and Prevention, 45, pp. 737-744, 2012.

[2] Hart, S. G., \& Staveland, L. E. Development of NASA-TLX (Task Load Index): Results of empirical and theoretical research. Human Mental Workload, ed. P. A. Hancock and N. Meshkati, Elsevier: Amsterdam, pp. 139-183, 1988.

[3] Reid, G. B., Potter, S. S., \& Bressler, J. R. Subjective Workload Assessment Technique, Armstrong Aerospace Medical Research Laboratory: USA, 1989.

[4] Yamaguchi, M. \& Sakakima, J. Evaluation of driver stress in a motorvehicle driving simulator using biochemical marker. The Journal of International Medical Research, 35, pp. 910-100, 2007.

[5] Shappel, S. A., \& Wiegmann, D. A. Human Factors Analysis and Classification System, Federal Aviation Administration: U.S. Department of Transportation, 2000.

[6] Iridiastadi, H., \& Ikatrinasari, Z. F. Indonesian railway accidents utilizing Human Factors Analysis and Classification System in determining potential contributing factors. Work, 41, pp. 4246-4249, 2012.

[7] Kumar, A., \& Sinha, P. K. Human error control in railways. Jourdan Journal of Mechanical and Industrial Engineering, 2(4), pp. 183-190, 2008.

[8] Kim, D. S., Beak, D. H., \& Yoon, W. C. Developing a computer-aided system for analyzing human error in railway operations. World Congress on Railway Research, Seoul, Korea. Accessed from http://hdl.handle.net/10203/7892, 2008. 
[9] Thiffault, P., and Bergeron, J. Fatigue and individual differences in monotonous simulated driving. Personality and Individual Differences, 34, pp. 159-176, 2003.

[10] Gander, P., Hartley, L., Powell, D., Cabon, P., Hitchcock, P., Mills, A., \& Popkin, S. Fatigue risk management: Organizational factors at the regulatory and industry/company level. Accident Analysis and Prevention, 43, pp. 573-590, 2011.

[11] Dorrian, J., Roach, G.D., Fletcher, A., \& Dawson, D. The effects of fatigue on train handling during speed restrictions. Journal of Transportation Research Part F9, pp. 243-257, 2006.

[12] Roach, G. D., Darwent, D., Sletten, T. L., \& Dawson, D. Long-haul pilots use in-flight napping as a countermeasure to fatigue. Applied Ergonomics, pp. 214-218, 2011.

[13] Spencer, M. B., Robertson, K. A., and Folkard, S. The development of fatigue/risk index for shift workers. Health and Safety Executive Research Report no. 466, 2006.

[14] Zhang, C., Varvarigou, V., Parks, P. D., Gautam, S., Bueno, A. V., Malhotra, A., and Kales, S. N. Psychomotor Vigilance Testing of Professional Drivers in the Occupational Health Clinic: a Potential Objective Screen for Daytime Sleepiness. Journal of Occupational and Environmental Medicine, 54(3), pp. 296-302, 2012.

[15] Schleicher, R., Galley, N., Briest, S., and Galley, L. Blinks and saccades as indicators of fatigue in sleepiness warnings: looking tired? Ergonomics, 51(7), pp. 982-1010, 2008. 